\title{
Historical Analysis of the Policy on the College Entrance System in South Korea
}

\author{
Hee Jun Choi ${ }^{1} \&$ Ji-Hye Park $^{2}$ \\ ${ }^{1}$ Department of Education, Hongik University, Seoul, Korea \\ ${ }^{2}$ Department of Education, Kookmin University, Seoul, Korea \\ Correspondence: Ji-Hye Park, Department of Education, Kookmin University, 77 Jeongneong-ro, Seongbuk-gu, \\ Seoul, 136-702, Korea. Tel: 82-2-910-4290 (office), 82-104-151-3755 (mobile). E-mail: jpark22@kookmin.ac.kr
}

\author{
Received: August 26, 2013 Accepted: September 29, 2013 Online Published: October 28, 2013 \\ doi:10.5539/ies.v6n11p106 URL: http://dx.doi.org/10.5539/ies.v6n11p106
}

The research is financed by (Kookmin University Research Fund).

\begin{abstract}
The national college admission system has quite frequently been altered in South Korea since Korea was liberated from Japanese colonial rule in 1945. Nonetheless, there are still many ways in which the national college entrance system can be improved. This article initially analysed and synthesized the issues associated with the Korean college admission system that successive regimes had to tackle, the relevant policy alternatives, and the ensuing consequences of the policy alternatives instituted by different regimes. Based on the analysis, the persistent key issues embedded in major screening factors in the college admission system were determined. Through this analytical lens, this study intends to delineate some possible future directions for the improvement of the college admission system. In conclusion, the government would be well advised to make a continuous effort to complement and stabilize the existing system, regardless of changes in the regime. In addition, the historical analyses of the Korean college admission system will contribute to providing education policy makers in other countries with insights and vicarious experience for the reform of their college entrance systems.
\end{abstract}

Keywords: college entrance system, policy changes

\section{Introduction}

The Korean people's passion for educating their children knows no bounds because they have directly experienced the powerful influence of education on socioeconomic status. Educational issues, therefore, generate much debate in Korean society, and the South Korean government is under high pressure to resolve such issues. Many stakeholders (e.g., government, parents, students, teachers and so forth) indicate that the topmost problems surrounding students' education are private tutoring, issues concerning inequalities, distrust in public education, and excessive performance pressure placed on students. Particularly, private tutoring is the priority issue because it results in the other issues mentioned above.

Private tutoring has been considered a major educational issue in South Korea since the 1960s. The ultimate aim of this form of tutoring - regardless of students' educational level-is to equip students to pass the college entrance exam; almost all students, even high performers, undergo private tutoring to score well on the college entrance exam and gain admission into a prestigious university. Over the years, South Korea has witnessed a steady increase in the volume of investment in private tutoring and the number of students undergoing it. Specifically, while private tutoring amounted to about eight hundred and thirty billion U.S. dollars in 2001, this amount doubled to approximately one trillion and seven hundred billion U.S. dollars in 2011 (Statistics Korea, 2012). Further, the expansion in private tutoring is closely interrelated with other major educational issues like inequality, distrust in public education, and excessive performance pressure placed on students.

Many researchers have indicated the widening gap between social classes from the standpoint of private tutoring expenses (e.g., Kim, 2007; Yang, 2005, 2006). This gap makes the poor feel an even greater sense of deprivation, leading to other social problems; the widening gap could lead to educational inequality as well as social inequality by causing gaps in educational outcomes (Shin \& Kim, 2010). Along with inequality, distrust in the public education system has become stronger. As mentioned above, there has been a rapid expansion in the 
volume of private tutoring, and many stakeholders have started to question the quality of public education; and improving the quality of education appears to be the need of the hour (Yoo, 2009). In addition, changes made to the college admission system highly affected high-school education in terms of the subjects included in the curriculum, the format of the tests, and so on; therefore, high school education remained in a distorted state. When these educational issues become embedded in the fabric of society, they become social issues. Consequently, people have demanded changes in educational policies, which has led to frequent and constant changes in major educational systems such as the college admission system and the school curriculum. These changes have eventually affected students, placing them under tremendous pressure. Middle and/or high school students in Korea spend most of their days and nights in school. In fact, after school hours, many of them go straight to private institutes or for tutoring classes, where they spend many hours, sometimes even until very late night. As a result, they have little time to talk, play, and interact with friends and family members. This life pattern has given rise to many mental problems in Korean students that manifest as excessive forms of school violence, bullying, and even suicide. Acts of school violence and bullying frequently appear in Korean newspapers, and it is reported that about $12 \%$ of adolescent suicides are due to depression associated with school results (Ministry of Education, Science and Technology, 2011). In addition, approximately $90 \%$ of Korean students feel unhappy (Chosun Daily Newspaper, August 12, 2011). Although a variety of educational systems and policies have been associated with these educational issues, the effect of the college admission system is particularly known to be significant (Yoon et al., 2002).

The college admission system is the most crucial of educational systems, and it has far-reaching effects on many aspects of education and on stakeholders. This system has a bearing on the subjects taught in high schools, the teaching methods used, the performance assessment methods employed, and so on. Needless to say, students and their parents are affected by this admission system because it determines how students should study and how parents should support their children. In addition, the college admission system affects not only secondary education but also primary education and even lower levels of education (Kang, 2006). This is because obtaining a college diploma has for long been considered prestigious in Korea, a means of upward mobility that is associated with higher wages. Therefore, the college admission system, which is the gateway to college, is at the very core of educational issues (Jeong, 2011).

The South Korean national college admission system has undergone frequent modifications ever since Korea was liberated from Japanese colonial rule in 1945. Major changes in the system have been made 14 times, and minor changes have been made almost every year, especially since the late 1980s (Kim, Jeong, \& Lee, 2009). Yet, there are many ways in which the national college admission system can be improved. This statement gives rise to the question of what the persistent key issues that have been raised but remain unsolved are. This question must be answered because it is a prerequisite for a consistent educational policy and necessary for the development of an optimized and sustainable national college admission system.

\section{Analytical Framework}

In general, educational policy is affected by multiple factors like the prevalent social, political, and economic environment of the time (Katz \& Kahn, 1978). According to Sabatier (2007), a policy stream is the result of a dynamic interaction among various elements over time, and involves a variety of stakeholders such as political leaders, interest groups, and individuals. From among the various relevant elements, Kingdon (2003) emphasized the stream of social problems, the stream of politics, and the stream of policy alternatives. The first comprises the conditions that cause defects in a particular system or policy, and focuses on why more attention is afforded to one particular problem than to others. The stream of politics is associated with transitions of political power and does not deal with either the stream of social problems or the stream of policy alternatives. The final stream, policy alternatives, is associated with the proposal of new ideas within the policy community.

In the case of South Korea, it is the political stream in particular that has played a crucial role in the formation and implementation of educational policy pertaining to the college admission system (Kang, 2007; Lee, 2005). Some problems inherent to the national college admission system are serious social issues resulting from Korean people's excessive academic elitism and diplomaism (Kang, 2007; Kim et al., 2009; Lee, 2005). In fact, successive Korean regimes, without exception, endeavored to present new national college admission systems as a means to induce social consensus by resolving pending educational issues (Kang, 2007; Lee, 2005). Accordingly, this study attempts to classify the historical background of the Korean college admission system from the perspective of the successive political regimes that aggressively attempted to improve the system. This historical classification has rarely been attempted by other researchers even though it is significant; major changes made to the system have been shown to be closely associated with sociopolitical fluctuations. 
On the other hand, public policy is usually characterized by ambiguity in terms of policy objectives, policy means and alternatives, and the idiosyncratic characteristics of policy stakeholders. Therefore, the process of policy formation and implementation cannot be explained succinctly (Kingdon, 2003; Sabatier, 2007). In a similar vein, it is difficult to conclusively identify the process of change of educational policies in the context of the Korean college admission system. Despite this difficulty, it is possible to outline the policy process, which consists of defining a policy problem from among many social problems, selecting feasible policy alternatives, and implementing and evaluating these alternatives (Sabatier, 2007). This logic can be applied in order to outline the educational policy process of the Korean national college admission system. In other words, the process of modification of the college admission system can be systematically analyzed according to a sequence of the main educational problems identified, the alternative policies, and the results of the implementation of these policies. In this study, we first analyze and synthesize the issues surrounding the Korean college admission system that successive regimes had to tackle, the relevant policy alternatives they adopted, and the ensuing consequences of the policy alternatives, as instituted by different regimes. Next, based on this initial analysis, we determine the persistent key issues embedded in major screening factors in the college admission system. Through this analytical lens, we aim to delineate possible future directions for the improvement of the South Korean college admission system. These analytical results and the implications derived from those would be valuable information for education policy makers in not only South Korean but also other countries in planning to reform their college admission systems.

\section{Syng-Man Rhee's Regime (1948-1960)}

Immediately after liberation in 1945, Korea was still influenced by the U.S. military government; therefore, Korean colleges adopted the American college admission system, which is characterized by the principle of noninterference. At the time, the president or dean of every college had the right to select college entrants, without government intervention (Jeong, Kang, Kim, \& Cho, 2007; Kang, 2007; Kim et al., 2009; Lee, 2005). Each college administered its own test as a principal method for screening applicants. These college-administered tests generally tested knowledge in four required subjects-Korean literature, English, mathematics, and social studies - and one or more elective subjects that were vocational in nature. At this time, the autonomy of Korean colleges was at its apex.

Higher education in South Korea expanded rapidly since 1945 due to the Korean people's passion for educating their children. However, sociopolitical turmoil at the time resulted in serious problems with the Korean college admission system: special favors being given to college students in obligatory military service, the Korean War, etc. (Jeong et al., 2007; Kang, 2007; Yoon et al., 2000). In the early stages of Rhee's regime, illicit admission was the most serious problem. Typically, illicit admission involves the admission of unqualified applicants through the selection of more students than the prescribed number for a college entrance quota and the admission of students whose parents have monetary or political power. This corruption in the college admission process lowered the quality of higher education, clearly exposing an issue of inequality that required immediate resolution. As a solution, a national qualifying test was proposed in order to screen unqualified applicants. Consequently, in 1954, Korean colleges began to use both the National College Admissions Unified Test and a separate college-administered test as an entrance screening system. The National College Admissions Unified Test assessed information in four required subjects (Korean literature, English, mathematics, and social studies) and one elective subject from either the sciences or vocational subjects. The college-administered tests covered only three required subjects-Korean literature, English, and mathematics-and one elective subject from the field of social studies, science, or vocational subjects.

The National College Admissions Unified Test was administered by the government and played the role of a preliminary test in qualifying applicants. Applicants who passed the test were eligible for the college-administered tests. Female applicants and veterans were exempted from the National College Admissions Unified Test. Even though this revised system sought to resolve the issue of illicit admission, it was not successful because of the following issues (Jeong et al., 2007; Kang, 2007; Kim et al., 2009). First, there was increased pressure on the applicants, which posed problems. Under the revised system, applicants had to undergo one more test than before. This made stakeholders, including the applicants, dissatisfied with the system. Second, illicit admissions persisted despite a systematic effort to resolve the issue. Several powerful politicians misused the system, enabling their children or relatives to fraudulently pass the preliminary test. Third, there was the issue of the leakage of test questions, which brought about public censure. Fourth, the issue of inequality also persisted because female applicants and veterans were exempted from the National College Admissions Unified Test. Consequently, this test was nullified in 1955, one year after its adoption.

In 1955, Korean colleges adopted a new college admission system: colleges either used the aggregate scores of 
all the college-administered tests and high school records, or used only students' grade percentile ranks in high school without the college-administered test (Jeong et al., 2007; Kang, 2007; Kim et al., 2009). The subjects covered by the college-administered tests were primarily Korean literature, English, mathematics, social studies, and science. Majority of the colleges used the college-administered tests and high school records as the main means of screening; supplementary metrics consisted of an aptitude test, interview, and physical checkup. Some colleges selected part of their entrants based solely on the student's high school percentile rank. This college admission system is notable in that, for the first time, a non-examination screening method was used to normalize high school education and pursue whole-person education.

However, this college admission system had a serious flaw (Jeong et al., 2007; Kang, 2007; Kim et al., 2009). Some colleges abused the non-examination screening option and selected more students than that dictated by their entrance quota; this was done as a means to solve financial problems, and it resulted in the selection of even unqualified applicants. This corruption accelerated the decline in the quality of higher education and broadened the academic ability gap between colleges. As already mentioned, only the major subject groups were tested in the college-administered tests, that is, Korean literature, English, mathematics, social studies, and science. Therefore, the high school curricula focused only on teaching these primary subject groups, which was contrary to the initial intention of normalizing high school education.

Major concerns about the college admission system in this regime were associated with the issue of inequality that was caused by the corrupt admission system and the demands made to normalize high school education. Until the late 1960s, competition for gaining admission to middle schools remained a severe problem, and elementary school students suffered from much tension and stress (Lee \& Jang, 2010). Therefore, the Korean public was mostly concerned with private tutoring for elementary school students, not for high school students, until the middle school entrance examination was eliminated in 1968. At that time, most stakeholders did not regard private tutoring as a serious educational issue.

\section{Chung-Hee Park's Regime (1962-1979)}

Bo-Seon Yun was the second President of South Korea, in power from 1960 to 1962. During his regime, there were no major changes made to the national college admission system. Chung-Hee Park obtained political power through a military coup in 1961 and became the President of South Korea in 1962. To justify the military coup, Park sought to overcome a national economic crisis, political crisis, and societal crisis by eliminating the corruption prevalent in Korean society (Kang, 2007). In an effort to eradicate social corruption, Park's military government attempted to reform higher education and officially intervened in the college admission process. The National College Admissions Qualification Test was adopted as the primary screening modality. From 1962 to 1963, Park's military government administered this test, and colleges used the scores to select applicants. The government restricted the number of applicants to $110 \%$ of the total college entrance quota. The subjects tested by this government-administered test remained the same. However, the test consisted of multiple choice questions only, in contrast to the earlier test which consisted of multiple choice, short answer, and essay questions. In 1962, colleges chiefly used the scores of the National College Admissions Qualification Test to select applicants; in 1963, they used the scores of both the National College Admissions Qualification Test and the college-administered tests.

Initially, the college admission system during Park's regime encountered some daunting challenges (Jeong et al., 2007; Kang, 2007; Kim et al., 2009). (1) The colleges whose quality of education provided was not on par with the capabilities of the applicants faced financial difficulties owing to the restriction of the number of eligible applicants to $110 \%$ of the total college capacity. This further widened the already existing gap between prestigious colleges and other less-renowned ones. Consequently, competition to enter a prestigious college intensified. (2) The colleges lost their autonomy in selecting applicants because the key screening factor was the applicant's score on the government-administered National College Admissions Qualification Test. This loss of autonomy was criticized by many people who attempted to preserve the autonomy of colleges. (3) The government-administered test contained only multiple choice questions; this was the principal cause of abnormal high school education that laid emphasis on rote learning. Although the format of the test was intended to eliminate bias and improve fairness, it had negative effects on high school education.

In 1964, Park's government restored the college-administered test system because their government-administered test system had created additional problems instead of resolving existing ones (Jeong et al., 2007; Kang, 2007). From 1964 to 1968, the main screening modality was the scores of the college-administered tests, which consisted of multiple choice and open-ended questions; as supplementary modalities, students were once again made to undergo a physical checkup and an interview. Some colleges even 
used their applicants' percentile ranks in high school in conjunction with the results of an aptitude test. Between 1964 and 1968, each college determined the subjects tested by the college-administered test, and screening was done without government intervention.

However, this second college-administered test system during Park's regime also had serious flaws (Jeong et al., 2007; Kang, 2007; Kim et al., 2009). (1) The system resulted in abnormal high school education because, now, the sole focus of high school education was on how to score well on the college entrance examination. Generally, the subjects tested by the college-administered tests were confined to three or four major subjects-Korean literature, English, mathematics, social studies, and science. Therefore, schools implemented distorted curricula, spending the highest number of hours on teaching only these subjects so as to increase the college acceptance rates of their students. (2) Applicants were confused about their preparation for the college entrance examinations, which was the cause of much stress, because each college adopted its own idiosyncratic admission process, and the subjects tested by the college-administered test changed, albeit in slight measure, almost every year. (3) Some private colleges selected more students than the number prescribed by the college entrance quotas in order to solve their financial problems. This illicit admission - which led to a marked decline in the quality of college education - extended beyond the realm of education to become a serious social issue.

In 1969, colleges and the government collaboratively implemented a college admission administration (Jeong et al., 2007; Kang, 2007; Kim et al., 2009). The main reason behind this governmental intervention was to prevent colleges from cheating on the admission process. The government presented a new college admission system, the third system under Park's regime. Now, the primary screening modalities were the College Admissions Preliminary Test, which consisted of multiple choice questions, and the college-administered main test, which consisted of open-ended questions. Under this system, it was difficult for colleges to cheat because the college-administered main test was only administered to applicants who passed the College Admissions Preliminary Test. In order to prevent the shortfall of applications for admission, the government flexibly controlled the number of applicants eligible for the college-administered main test. The College Admissions Preliminary Test was used for multiple purposes. From 1969 to 1972, its only use was the advance screening of unqualified applicants. From 1973 to 1978, colleges used the scores of the College Admissions Preliminary Test and the college-administered main test to select applicants. From 1979 to 1980, the high school grade percentile ranking was added to the selection process. The subjects tested by the college-administered main test remained the same, while the College Admissions Preliminary Test added subjects such as social studies, science, national history, foreign language, and vocational subjects.

Despite governmental efforts, the revised college admission system also generated serious educational and social issues (Jeong et al., 2007; Kang, 2007; Kim et al., 2009). (1) Abnormal high school education was widespread. As the students of the baby boom generation became college prep students, competition to enter a prestigious college further intensified. This provoked many high schools to tailor their curricula to focus only on the main subjects tested in the college entrance tests. (2) The college-administered main test consisted of difficult open-ended questions, and students started enrolling in expensive private tutoring to pass these tests. The cost of private tutoring was frequently beyond the average family's monetary means. Because the information tested in the college-administered main test was far beyond the level of a high school curriculum, applicants were compelled to enroll in tutoring classes despite their high costs. This was one of the most serious social issues faced at the time. (3) The burden on the applicants increased considerably because now, they had to take two tests. This resulted in the emotional instability and dehumanization of high school students. Barring minor changes, this third college admission system was used for 12 years, even though it had serious social repercussions.

During Park's regime, the major focus of policy changes to the college admission system was on "who has the hegemony in selecting college students." First, this was the prerogative of the government; then, it was the individual colleges. Finally, there was collaboration between the government and colleges. In sum, when the government had hegemony, the admission test mainly consisted of multiple choice questions; when the college had hegemony, the test comprised both multiple choice and open-ended questions, focusing on a few major subjects. The changes in test format significantly affected high school education: either there was a focus on rote learning or there was a focus on the few subjects assessed by the college admission tests. Therefore, the quality of high school education was problematic throughout the regime. In addition, private tutoring became a major educational issue because of increased competition for college entrance.

\section{Doo-Hwan Chun's Regime (1980-1988) and Tae-Woo Roh's Regime (1988-1993)}

After President Park's assassination on October 26, 1979, Kyu-hah Choi became the acting president for 
approximately eight months. Due to his short stint as President, there were no major changes made to the national college admission system. In this section, we address two regimes (i.e., Chun's regime and Roh's regime) together because the basic framework of the college admission system in Roh's regime was similar to that in Chun's regime.

Immediately after Chun came into power in 1980, he attempted to reform the entire educational system, including the national college admission system. At that time, the most worrying social-cum-educational concerns of the Korean people were high private tutoring costs and excessive competition for college admission (Jeong et al., 2007; Kang, 2007; Kim et al., 2009). Therefore, Chun attempted to enhance his political stature by announcing an innovative educational reform in 1980: the "7.30 Educational Reform." The key functions of this reform were to prohibit all kinds of private tutoring by national law, abolish the college-administered main test, and increase the college entrance quota by $30 \%$ through a graduation quota policy aimed at restoring the initial goals and functions of high school education.

In 1981, Chun's regime adopted the government-administered test system based on the "7.30 Educational Reform." Under this system, the main screening modalities were the College Admissions Preliminary Test and the high school percentile rank. Applicants now had to take only one government-administered test. Additional notable points of the system were that applicants had to decide on colleges to apply to after getting the results of the College Admissions Preliminary Test. Students were allowed to apply to multiple colleges of their choosing, without limitations. The co-requisites of the College Admissions Preliminary Test were seven subjects-Korean literature, national history, mathematics, Chinese classics, national ethics, politics and economics, and industrial technology or household management. The co-elective subjects were one foreign language subject, including English, and one vocational subject. Additionally, five more subjects were included in the test.

Despite ambitious efforts toward educational reform, the new college admission system brought about several problems (Jeong et al., 2007; Kang, 2007; Kim et al., 2009). (1) The high school grade percentile ranking, one of the main screening factors, proved to be problematic because it did not consider the academic discrepancies among high schools; therefore, it resulted in more intense competition among students of the same school. (2) The $30 \%$ increase in admissions due to the changes in the graduation quota policy led to a marked decline in the quality of higher education. This was because the graduation quota policy was not strictly implemented as intended and was simply used as a tool to increase the college entrance quota. (3) Some colleges could not meet the prescribed number of enrollment because of the prior-test and the post-application system, and the multiple college application procedure. This issue had the potential to greatly exacerbate the academic and financial gaps among colleges.

In 1982, the government presented a partially revised college admission system that used the College Admissions Scholastic Achievement Test (CASAT) and the high school grade percentile ranking as the main screening factors. The CASAT was a government-administered test and the new name given to the former College Admissions Preliminary Test. This new test was used throughout Roh's regime, until 1993, even though the number of subjects it tested changed frequently. The CASAT assessed performance in 14 subjects in 1982 and 1983, 15 in 1984, 16 in 1985 and 1986, and 9 from 1987 to 1993. The government attempted to improve the admission procedure whereby students could apply to multiple colleges. In order to prevent colleges from not meeting the prescribed number of enrollment, the number of colleges to which applicants could apply was limited to two in 1982 and one from 1983 onward.

In 1986, the college admission test included an essay as a screening factor, and each college was allowed to administer an essay of their choice. The essay format was adopted for the following reasons (Jeong et al., 2007; Kang, 2007; Kim et al., 2009). First, the CASAT was under considerable criticism because it focused on measuring applicants' rote memory skills and fragmentary knowledge. The need of the hour was a new test format that would measure applicants' higher-order thinking abilities or creativity. Second, many people asserted that the government-administered test system infringed on the autonomy of colleges in selecting students. Therefore, the government had to give colleges partial rights to select candidates. However, the essay test was only used for two years, from 1986 to 1987, because there were serious concerns about the validity of the essay topics.

In 1988, Tae-Woo Roh was elected president, and his government immediately changed the college admission system. First, short answer questions were included in the CASAT to partially compensate for the shortcomings of only multiple choice questions. Second, the prior-test and the post-application procedure were changed to the first-application and post-test procedure in order to change the prevalent wait-and-see application system. This proved to have relatively positive results and allowed students to apply to colleges based on their academic 
abilities. Third, an interview stage was included as a supplementary screening factor. Each college could reflect the result of an interview within $10 \%$ range. Finally, in order to reverse the decline in the quality of higher education, the government abolished the old graduation quota policy that had increased the college entrance quota by $30 \%$. Although the college admission system during Roh's regime was intended to resolve existing educational problems, the root problems remained unresolved. The most typical of these problems were the distortion of high school education owing to its focus on rote learning and the college entrance test, excessively intense competition among students, distrust in the high school grade percentile ranking as it disregarded the academic discrepancies among high schools, etc. (Jeong et al., 2007; Kang, 2007; Kim et al., 2009). In Chun and Roh's regimes, efforts to enhance the college admission system were heavily associated with prohibiting private tutoring and then normalizing high school education by relying on standardized tests that focused on school textbooks. However, several basic educational issues were not completely resolved.

\section{Young-Sam Kim's Regime (1993-1998)}

Young-Sam Kim, elected in 1992, was the first civilian President of South Korea in 30 years. In February 1994, he formed the Presidential Committee for Education Reform, which initiated four major educational reform plans before February 1998. The Committee proposed an aptitude test for higher education, which was later referred to as the "College Scholastic Ability Test" (CSAT), along the lines of the Scholastic Aptitude Test (SAT) in the U.S. The CASAT, adopted in 1982 as a government administered test, could no longer last because of criticism that the test focused primarily on measuring students' textbook-based rote memory on subjects included in the high school curriculum (Kang, 2007). Accordingly, the CSAT was proposed with the intent of measuring students' higher order and analytical thinking skills (which are the main goals of high school education) so that colleges could screen students with the relevant academic capabilities for higher education (Jeong et al., 2007). People believed that short-term private tutoring would not be effective under this system because the capabilities measured by the CSAT could not be enhanced in a short period of time. At that time, private tutoring was legally permitted because prohibiting it was found to be unconstitutional. The CSAT consisted of four parts-language, mathematics I, mathematics II, and foreign languages. Of the total 200 points, $70 \%$ constituted multiple-choice questions, and 30\% were open-ended questions. Therefore, in design, it went beyond the scope of the textbook and was expected to play a role in suppressing private tutoring, thereby normalizing high school education. The scoring system was multi-faceted and consisted of various components such as the raw scores and percentile ranks of each part and the total raw score and percentile rank of the four aggregated parts.

Colleges could now screen students using various combinations of the CSAT, high school grade percentile ranking, and college-administered test. They could choose not only screening factors but also the degree to which each factor was reflected (Jeong et al., 2007). Additionally, colleges could use various formats of college-administered tests such as an essay test, an aptitude test, and an interview (Kang, 2007). Although colleges had expanded their autonomy in the admission system at this time, they still faced some restrictions: the percentage of high school grade percentile ranking reflected could not be less than $40 \%$, and the college-administered tests could not assess the three major subjects of Korean literature, English, and mathematics in order to normalize high school education.

Despite significant revisions made to the college admission system, there remained several problems (Jeong et al., 2007; Kang, 2007; Kim et al., 2009). (1) Academic discrepancies among high schools could not be reflected in the high school grade percentile ranking, making it difficult to screen academically eligible students in an unbiased manner. (2) The grade percentile rank scoring system was problematic. The rank was calculated using a two-step process: converting the total raw score of high school grades into the perfect score of 100, and then converting the score into a five-letter grade. Because of the gap between the total raw score and the letter grade, it became difficult for high schools to compute students' ranks. (3) The new admission system, counter to the intention of the revision, imposed an even greater burden on students because they now had to study every subject in the school syllabus and actively participate in various learning activities in order to obtain a good high school grade percentile rank. (4) High school education continued to focus on helping students to get into a college, and therefore remained abnormal.

Because of the problems stated above, the college admission system was again revised in 1997. Although the CSAT was continued, the scoring system was significantly altered. The total score was expanded to 400 points by adding more test items in order to better assess the students' academic level. In addition, various types of test scores were reported, such as raw score, percentile rank, standardized score, transformed standardized score, and percentile rank by standardized score. The most significant change made at this time was the inclusion of expanded high school records consisting of 13 components, including personal information, academic records, attendance records, and award-winning records. Therefore, instead of only focusing on academics, the revised 
high school records now comprehensively assessed students' overall capabilities. Some changes were also made to the college-administered tests. National and public colleges were prohibited from administering such tests, except for a type of essay test, and the formats of the college-administered tests varied (Ministry of Education, 1995).

However, again, the revised college admission system was not flawless (Jeong et al., 2007; Kang, 2007; Kim et al., 2009). First, it was very difficult to develop questions for the CSAT that aimed to test higher order and analytical thinking and yet maintain the quality and difficulty level of the test. Second, there were concerns about the reliability and validity of the comprehensive high school records because of discrepancies among high schools. In fact, many high schools attempted to inflate their records to help more students gain admission into colleges. There were also reservations regarding the use of comprehensive high school records for college screening. Finally, the academic gap among colleges expanded because colleges relied heavily on the CSAT score for screening.

The major change to the college admission system in Kim's regime was the adoption of the CSAT. This was expected to play a significant role in normalizing high school education. Instead, it resulted in the explosive increase of private tutoring and distrust in high school education because students could not effectively prepare for the CSAT with school education alone.

\section{Dae-jung Kim's Regime (1998-2003) and Moo-hyun Roh's Regime (2003-2008)}

From the mid-1990s, the expansion in private tutoring became a major concern in South Korea. Even students at the primary and lower secondary levels attended private tutoring classes, and parents complained about the significant financial burdens associated with these classes (Seo, 1997). Furthermore, in 2000, the South Korea Constitutional Court declared the prohibition of private tutoring to be unconstitutional. The sustained growth of private tutoring has been at the center of controversy ever since, and problems associated with it have seriously affected educational policy pertaining to the college admission system.

The college admission system established by Young-Sam Kim's regime remained in use until 2001. Dae-jung Kim made significant revisions to the system in 2002 in order to tackle pending educational issues, including the expansion of private tutoring. The revised system was used until 2007. During Roh's regime, an educational reform plan including the revision of the college admission system was proposed in 2004 and was made to be in effect in 2007. Roh's regime was terminated, and the government transited to incumbent president Lee in 2008. President Roh's new college admission system, therefore, was in effect for only one year. Therefore, the college admission systems adopted in the reigns of Dae-jung Kim and Moo Hyun Roh must be discussed simultaneously.

The most significant changes made to the college admission system at this time were the adoption of a non-examination screening system and the diversification of screening modalities (Kang, 2007). Although the government prohibited all colleges from implementing college-administered tests focusing on cognitive achievement, the autonomy of colleges was expanded in other respects of the screening system. Colleges could decide on the use and ratio of the comprehensive high school records being reflected in the screening system. Additionally, the formats of college-administered tests were diversified to include, among others, a statement of purpose, interview, essay, and aptitude test.

The overall format of the CSAT remained unchanged, barring some modifications to specifications of the scoring system and the subjects included in the test. The new scoring system was based on the standard nine (stanine) scoring method on a nine-point standard scale, with a mean of five and a standard deviation of two. Standardized scores and percentile scores of subjects, in addition to the stanine grade, were used to provide information pertaining to personal aptitude. This new scoring system appeared to contribute to the partial elimination of the problematic ordering of test scores (Kang, 2007). In terms of subjects included in the CSAT, a significant change was made in 2005 as a result of the implementation of the Seventh National Curriculum Reform, which was adopted in 2003. A vocational component was added, and the "foreign languages" component was renamed as "foreign languages/Chinese classics." Thus, students had more options in terms of the subjects and parts to be selected for the CSAT.

Although many efforts were made to resolve the pending problems in education, many remained unsolved or had exacerbated (Jeong et al., 2007; Kang, 2007; Kim et al., 2009). (1) The CSAT was not fully accepted as a good indicator of student screening: the reliability and validity of the test remained questionable. (2) The government gave colleges greater autonomy in student screening in order to develop students' aptitude by diversifying the screening modalities. However, many colleges relied heavily on the CSAT score because it was a common measure and an easy one with which to rank students merely using their test scores. Additionally, the diversification of screening methods-which was proposed to develop students' varied aptitudes-failed to 
achieve its initial goal because of problems such as subjectivity and bias. (3) The essay test administered by each college tended to become a cognitive achievement test that was only tangentially related to the three major subjects; hence, this led to an expansion in private tutoring. (4) The problems associated with comprehensive high school records persisted. High schools continued to exaggerate their student. Further, academic discrepancies among high schools were not reflected in the comprehensive high school records, and many stakeholders indicated its inappropriateness as a screening method.

The major changes to the college admission system in these regimes can be summarized as the diversification of the college admission system and the expansion of college autonomy for screening students. These changes were intended to allow students to enter colleges not based on their test scores but based on their diverse capabilities. By doing so, it was expected that students would not need private tutoring to obtain high test scores, thereby normalizing high school education. The end result, however, was that this expectation was not met. Expenses for private tutoring almost doubled from 1998 to 2005 (KEDI, 2009), and distrust in public education deepened.

\section{Myung-bak Lee's Regime (2008-Present)}

In 2007, in the last year of his regime, Roh implemented a plan for advancing the college admission system. According to the plan, the results of the CSAT were to be reported only according to rank, not according to raw score; further, colleges were encouraged to increase the ratio of the comprehensive high school records reflected on the college admission. However, this plan was discontinued after only one year due to the transition of the government to Myung-bak Lee.

Lee's government value was "excellence in education" as opposed to the previous regimes', which was "equality in education" (Seo, 2009). Therefore, the emphasis on excellence in education affected all policies on the college admission system. The government announced a three-phase plan to provide complete autonomy to colleges in the admission system. The first phase involved the Ministry of Education, Science, and Technology handing over most duties pertaining to the college admission system to the Korean Council for College Education. The second phase involved the expansion in the use of admission officers as a main screening method. The final phase involved providing complete autonomy to colleges by 2012. Although implementation has not gone according to plan, the government continues to strive to meet this three-pronged goal.

The most noticeable change made to the college admission system in this regime is the expansion in the use of admission officers. The admission officer system is defined as "the screening system in which each college hires admission officer(s) who have extensive knowledge about high school curriculum and screening systems and lets them select students on the basis of their grades, personal background, potential, and aptitudes" (Ministry of Education and Human Resource Development, 2007). The admission officer system was adopted with the intention that high school education could be normalized because students will not have to compete with one another merely on the basis of test scores, and colleges will be able to select students with various aptitudes based on diversified and distinctive selection standards (Ministry of Education and Human Resource Development 2007). Although admission officers were first introduced by Roh's government in 2004, it was Lee's government that actively encouraged colleges to adopt the admission officer system. In his 2009 address broadcast on the radio, President Lee predicted that by the end of his tenure, almost $100 \%$ of higher education institutes would employ the admission officer system (Yonhap News, July 27, 2009). Thus far, 120 of 411 higher education institutions in South Korea have adopted this system (Korean Council for College Education n.d.).

It is difficult and perhaps even inappropriate to discuss the success or failure of this new admission system based on the results generated in so short a period of implementation. Many stakeholders anticipate that the admission officer system may solve many of South Korea's endemic problems - such as high private tutoring expenses and the rising academic gaps among colleges - by using diverse selection factors for admitting students into college, aside from academic grades. Further, admission officers or admission specialists will now take full responsibility for the selection process (Park 2009). Many stakeholders, however, have concerns about the heavy reliance on the admission officer system because of its subjectivity and the low level of trust in admission officers thus far (Park, 2009).

Another noticeable change made to the college admission system, in particular to the CSAT, was announced in 2011 and will be in effect in 2014 (Ministry of Education, Science, and Technology, 2011). The government intends to significantly revise the CSAT in many aspects based on the view that the current CSAT imposes a very severe burden on students and the fact that the newly updated curriculum in 2009 needs to be reflected in the test. First, the number of subjects will be reduced: From 2014, students will study only up to five subjects - Korean literature, mathematics, English, and social studies or sciences (up to two elective subjects) - compared to the seven subjects from five domains studied in 2012, that is, languages, mathematics, foreign languages, social 
studies or sciences, and foreign languages II/Chinese classics. In addition, from 2014, students will be able to choose from between two difficulty levels (i.e., A and B) with regard to Korean literature, mathematics, and English. Type A will be easier and will cover a narrower range of topics compared to type B. For selection, colleges will also be able to choose from among various combinations of difficulty levels for subjects, according to academic disciplines and students' academic abilities. For example, a university can use the type B CSAT score for Korean literature, the type A mathematics score, and the type B English score for students who want to apply to the Department of Humanities, while the same university can use the type A CSAT score for Korean literature, the type B mathematics score, and the type B English score for students who want to apply to the Department of Engineering. Because the new CSAT has not yet been implemented, it cannot be assessed. Many stakeholders, however, are anxious that the type A CSAT may make the college-administered test more difficult in order for colleges to screen students with appropriate academic abilities. Further, students may end up preparing for both difficulty levels at the last moment in order to better their chances of gaining admission to colleges of their preference, because it is obvious that most prestigious colleges will select as many type B scores as they are allowed. After all, it can be said that the current state of high school education in Korea remains distorted because it focuses only on the subjects assessed by the CSAT and college-administered tests (Yonhap News, August 19, 2010).

\section{Syntheses and Implications}

Successive Korean regimes have attempted to adopt their own unique college admission systems in an effort to solve the serious problems associated with secondary education. Historically, changes in the college admission system were closely associated with diverse combinations of screening factors. These screening factors can be categorized as college-administered tests, government-administered tests, and high school records, despite frequent changes made to their titles, formats, weights, or scopes. In this concluding section, we address key issues that have persisted throughout successive regimes from the perspectives of the three major screening factors. Doing so will provide insights for possible future directions for the improvement of the South Korean college admission system.

\subsection{Government-Administered Tests}

The names given to the government-administered tests were changed across regimes. The first such test was called the "National College Admissions Unified Test," which was changed to the "National College Admissions Qualification Test," "College Admissions Preliminary Test," and "College Admissions Scholastics Achievement Test." The current name, "College Scholastic Ability Test (CSAT)," has been in use since 1994. Along with changes in the name, the principal objectives of the tests were also changed. Some of the tests aimed to measure students' academic abilities or achievements, such that the results could be employed as either a main screening factor or a supplementary screening factor. Other tests aimed to filter out unqualified students for higher education. The subjects covered by the tests also changed over regimes. Some tests assessed only three or four major subjects, while others tested up to 16 subjects. In terms of test format, some tests comprised only multiple choice questions, while others contained a mixture of multiple choice and short-answer questions.

According to our analysis, despite frequent changes in the titles, formats, and scopes of the government-administered tests, some common problems persisted throughout successive regimes. (1) The government-administered tests were mainly in multiple-choice question format-except for a few years during which short-answer questions were added - because the multiple choice format had crucial advantages in terms of ready scoring and objectivity. In order to obtain a better score on the test, high school students had to focus on simply understanding and memorizing knowledge in the textbooks; thus, high school education remained in a distorted state because of its focus on rote learning. (2) The difficulty levels and validity of the government-administered test have always been controversial. Difficulty levels fluctuated and frequently did not match the level announced by the government. Therefore, high school students and teachers were confused about how to prepare for the test, and private tutoring proliferated. The validity of the test was also a problem. The CSAT was intended to extend beyond the mere reproduction of the contents of a textbook; it aimed to measure students' higher-order thinking such as analytical thinking, problem solving, and global thinking abilities. However, it is not easy to measure such abilities through multiple choice questions. Therefore, there was much debate about whether the test actually measured these abilities, thereby achieving its objective. (3) Other concerns were raised about the number of subjects included in the government-administered tests. When only a few subjects were included, there were concerns that high school education remained in a distorted state because of undue focus given to the delivery of those subjects, while other subjects necessary for the proper psychological development of students were neglected. When a large number of subjects were included in the test, conversely, there were concerns that there was too much burden imposed on students. All things considered, 
the revisions in the number of test subjects failed to assuage stakeholders' concerns regarding the suppression of private tutoring and the normalization of high school education.

\subsection{College-Administered Tests}

Various types of college-administered tests were administered since 1945. These include an academic achievement test administered by individual colleges, an essay test, an aptitude test, an oral test, and a practical test. An analysis of the history of the Korean college admission system reveals that from among the various college-administered tests, the academic achievement test and the essay test are the most critical and controversial screening factors. In particular, these two tests were intended for every applicant and were given significant weight as crucial screening factors.

The initial college-administered test focused on measuring applicants' academic achievements in three major subjects: Korean literature, English, and mathematics. Additionally, the test mainly consisted of open-ended questions with a high difficulty level. These college-administered tests were a key screening factor from 1945 to 1980, even though they were temporarily abolished in 1962. After the college-administered test to measure applicants' academic achievement was abolished in 1981, the government-administered test was the main screening factor. In 1986, an essay test was introduced in order to compensate for the shortcomings of the government-administered test. However, the essay test, which was administered by each college, lasted for only two years because inexperience in setting these tests by each college resulted in serious implementation problems. From 1994, the essay tests were once again used as one of the main screening factors, with the official restriction that the topics should not be related to major subjects such as Korean literature, English, mathematics, and so on.

Despite the many fluctuations in the college-administered test system, the essay test-the current college-administered test-still has problems that require resolution. First, most colleges have not established a clear rubric by which applicants' answers in the essay test can be fairly assessed. This results in inter-rater reliability issues and causes stakeholders to strongly distrust the reliability of this test. Second, applicants find it difficult to effectively prepare for the essay test through the existing high school curriculum, as each college independently formulates questions for the essay test with different tendencies, range, and difficulty levels (Lee, 2005; Lee, 2008; Shin, 2005). Therefore, applicants' dependency on private tutoring increases, despite its high costs.

\subsection{High School Records}

High school records have been one of the major screening factors in the college admission system since 1955, with the exception of a few years in between. Earlier, high school records were used in the form of percentile ranks. Specifically, students were ranked on the basis of their academic performance within a high school, and a letter grade was assigned to students falling within a certain range. The scales of the grade (e.g., 1 to 10,1 to 15 ) varied over time. High school records, which are primarily based on academic performance, were significantly altered and expanded in 1997. The expanded high school records were designed to contain information not only on academic performance but also on various components such as award-winning records, certificates, and records of volunteer community services. These changes were incorporated so that high school records could more accurately reflect students' various aptitudes or specialties when considering college admission.

Despite the crucial role played by these records in the college admission system, there remain many associated problems, as discovered in this study. First, the reliability of high school records as one of the main screening modalities is questionable. Because students' academic performances vary significantly depending on the high school they attend, it is difficult for colleges to use only high school records to screen students with the required level of academic capabilities for higher education. Additionally, there have been some incidents in which high schools have inflated some students' high school records so that these students stand a better chance of being accepted in a prestigious college. Second, some components of high school records are based on student outcomes obtained from competition among students within a single school. Competition among students in the same high school, therefore, has persisted or even intensified. This is because high school records cannot be shown to be reliable, thus dehumanizing high school education.

\subsection{Implications}

Most Koreans regard education as the tool by which to enhance social status because they have directly experienced the powerful influence of education on socioeconomic status (Kim, 2003). This belief has given Koreans a passion for educating their children; for the Koreans, the highest possible priority is placed on securing admission to a prestigious college. Consequently, society, at large, has paid a great deal of attention to 
the college admission system, which has frequently been at the center of social controversy. Successive regimes, therefore, have striven to improve the college admission system through frequent modifications in differing combinations of main screening factors and their specifications.

In reality, however, it seems difficult to resolve the problems embedded in the major screening factors all at once. The purpose and scope of each of the three screening factors need to be independently clarified in an initial effort to stabilize the college admission system. This is because the complex and interrelated issues discussed above cannot be resolved with only a single screening factor. The government-administered test should aim to focus on normalizing high school education and provide fair and objective information regarding applicants' academic abilities. The test would then be efficient if it focused on the multiple-choice question format that is convenient to score (Roediger III \& Marsh, 2005) and would be effective if it covered most of the subjects included in the high school curriculum, even though this might result in other issues such as increased burden on students and rote learning (Glover, 1989; Kulhavey, Dyer, \& Silver, 1975; Kuo \& Hirshman, 1996). However, the burden on students would not necessarily be increased if the difficulty of the questions was restricted to a moderate level for the purpose of measuring applicants' basic academic abilities. The issue of rote learning can be resolved by other screening factors such as college-administered tests and high school records, as opposed to a government-administered test consisting of multiple choice questions.

The college-administered test should aim to measure applicants' higher-order thinking abilities that are closely associated with the subjects included in the high school curriculum; this would, paradoxically, resolve the issue of private tutoring. In order to achieve this ambitious aim, the test should consist of authentic problem-solving questions that students will be unable to solve without a fundamental understanding of the subject being tested. The current trend of keeping the test material unrelated to the subjects taught in high school would more likely result in the proliferation of costly private tutoring because high school teachers will not be able to cover such extensive subjects and topics, considering the limited time and resources available to them. Further, the test questions should be set from information available within the high school curriculum so that high school teachers can focus on providing instruction on root principles rather than the superficial knowledge of subjects. This would contribute to getting high school education back on track. Additionally, each college needs to devote more time and resources in setting up test questions with clear rubrics for scoring. Currently, only a few faculty members set test questions within a short span of two weeks or less; this will not prove to be helpful in fixing the problems of inter-rater reliability and restoring the stakeholders' trust. Therefore, a college-administered test with a clear and reliable rubric for scoring would provide high school teachers with direction on how to guide their students.

In essence, high school records reflect a student's progress in school. However, academic discrepancies among high schools have resulted in stakeholders' distrust and dissatisfaction with the reliability of high school records, despite the positive intentions thereof. Nonetheless, high school records have become more significant in the college admission system. Thus far, the policy on high school records being reflective in the college admission system has focused on uplifting students from high schools in relatively underdeveloped areas, so that they can have an equal or even better chance of gaining admission into colleges. However, this has led to reverse discrimination against students with outstanding academic achievements, belonging to academically developed or specialized high schools. In order to solve this issue and to increase the reflection rate of high school records, the government needs to tactfully reexamine the policy regarding the equalization of high schools. In December 2011, the Ministry of Education, Science, and Technology announced in a press release that the current norm-referenced evaluation system for high school students (i.e., grade percentile rank) would change to the criterion-referenced evaluation system. According to the new system, students will receive a credit rating from A to F based only on whether they achieve learning objectives in each subject. In other words, students will have only to focus on their own learning rather than competing with their peers (Ward, 1970). The new evaluation system will be in effect for students who become high school freshmen in 2014 and be reflected in the college admission system from 2017. This new system may resolve the issue of reverse discrimination and intensified competition among students. However, it is predicted that students' high school records may be inflated, and colleges may impose college-administered tests with higher difficulty levels in order to screen students with the required academic capability. The most important implication of our analysis in this study is that it is difficult, and probably impossible, to establish a flawless college admission system that will satisfy society at large. In other words, implementing a new college admission system may not prove to be the optimal strategy, regardless of the system being proposed, because history has shown that all the new systems implemented over the years have ushered in unintended problems or controversies. Moreover, many of the issues inherent to the systems have appeared repeatedly, over successive regimes. In fact, as seen from this study, the adoption of new systems 
has only served to intensify confusion, resulting in a considerable waste of time and money. Therefore, the government would be well advised to make continuous efforts to complement and stabilize the existing system, regardless of possible changes in regime.

This study is limited to analyze the history of the college admission system only in South Korea. Nevertheless, the findings of this study will provide insightful implication for policy makers or researchers because a historical review of college admission systems of other countries would be valuable information in order to improve or optimize their own system. In addition, this study plays a significant role in providing researchers with a comprehensive understanding of the South Korean college admission system, which is roughly known to be "a centralized exam and placement approach" and like China, Taiwan, and Turkey (Tung, 2009, p. 2). It is certain that the college admission systems that such countries are adopting would have not only similar features but also distinctive features. This means that a comparative approach comparing several countries' college admission systems would be interesting. Accordingly, further research studies need to be conducted with this approach on the basis of the results of this study.

\section{References}

Glover, J. A. (1989). The "testing" phenomenon: Not gone but nearly forgotten. Journal of Educational Psychology, 81, 392-399. http://dx.doi.org/10.1037/0022-0663.81.3.392

Jeong, J., Kang, T., Kim, S., \& Cho, K. (2007). Direction for improving the college admission system after 2008. Korean Council for University Education, RR2007-11-265.

Jeong, W. (2011). A study on Korean college exams from the aspects of fairness and educational aims. Society \& Philosophy, 21, 107-140.

Kang, C. (2006). A sociological study on school career capitalization of Korean elementary education. The Journal of Research in Education, 26, 101-123.

Kang, C. (2007). The socio-historical development and characteristics of the university admission systems in South Korea. The Journal of Research in Education, 28, 83-113.

Katz, D., \& Kahn, R. L. (1978). The social psychology of organization (2nd ed.). New York: John Wiley \& Sons.

Kim, J. (2003). Inequality in education in the Korean society. Economy and Society, 59, 55-77.

Kim, M., Jeong, K., \& Lee, H. (2009). A study on the college admission system for liaison between high school education and higher education. Korean Educational Development Institute, RR2009-19-2.

Kingdon, J. (2003). Agendas, alternatives, and public policies (2nd ed.). New York: Longman.

Korean Council for University Education. (n.d.). Statistics of admission officers. Retrieved from http://uao.kcue.or.kr/info/status.jsp

Kulhavey, R. W., Dyer, J. W., \& Silver, L. (1975). The effects of notetaking and test expectancy on the learning of text material. Journal of Educational Research, 68, 363-365.

Kuo, T. M., \& Hirshman, E. (1996). Investigations of the testing effect. American Journal of Psychology, 109, 451-464. http://dx.doi.org/10.2307/1423016

Lee, J. (2005). History of the college admission system. Seoul: Korean Institute for Curriculum and Evaluation.

Lee, W. (2008). A study of the validity of the essay test as a college admissions screening factor in Korea: Evaluative approach to validation (Doctoral dissertation, University of Illinois at Urbana-Champaign).

Ministry of Education. (1995). An implementation plan of the new college admission system.

Ministry of Education and Human Resource Development. (2007). A plan for supporting the admission officer system in order to advance the university admission system. Seoul: Ministry of Education and Human Resource Development.

Ministry of Education, Science, and Technology. (2011). A revision plan of the 2014 College Scholastic Ability Test (press release).

Ministry of Education, Science, and Technology. (2011). The evaluation system change of high school records (press release).

Park, H. (2009). The possibilities and limitations of admission officers in college entrance examination of Korean universities. The Korean Journal of Educational Methodology Studies, 21(1), 11-46. 
Roediger III, H. L., \& Marsh, E. J. (2005). The positive and negative consequences of multiple-choice testing. Journal of Experimental Psychology: Learning, Memory, and Cognition, 31, 1155-1159. http://dx.doi.org/10.1037/0278-7393.31.5.1155

Sabatier, P. A. (2007). Theories of the policy process. Boulder, CO: Westview press.

Seo, C. (2009). Future tasks of Myung-bak Lee's government education reform implementation. The Journal of Educational Administrations, 27(2), 481-499.

Seo, N. (1997). Measures against overheated private tutoring. Journal of Economics and Finances of Education, $10,361-370$.

Shin, J. (2005). Essay test and the autonomy of universities. Philosophy \& Reality, 66, 116-121.

Tung, C. Y. (2009). College admissions under a centralized entrance exam: A compromised solution. Retrieved from http://www.econ.sinica.edu.tw/upload/file/Chris\%20Y_\%20Tung.pdf

Ward, J. (1970). On the concept of criterion-referenced measurement. British Journal of Educational Psychology, 40, 314-323. http://dx.doi.org/10.1111/j.2044-8279.1970.tb02137.x

Yonhap News. (2009). Significant change on the university admission system by 2013.

Yonhap News. (2010). Drastic change on the College Scholastic Ability Test. Will Students' burden be reduced?

Yoon, J., Song, K., Cho, D., \& Kim, B. (2002). Issues of education policy (Korean version). Seoul: Gyoyukgwahaksa.

\section{Appendix}

Table 1. Summary of the college admission systems in Korea

\begin{tabular}{|c|c|c|c|c|c|}
\hline \multicolumn{3}{|c|}{ Regimes and issues } & \multicolumn{3}{|l|}{ Screening factors } \\
\hline Regime & Year & $\begin{array}{l}\text { Major issues to } \\
\text { be resolved }\end{array}$ & $\begin{array}{l}\text { Government-administered } \\
\text { test }\end{array}$ & $\begin{array}{l}\text { College-administered } \\
\text { test }\end{array}$ & $\begin{array}{l}\text { High school } \\
\text { records }\end{array}$ \\
\hline \multirow{3}{*}{$\begin{array}{l}\text { Syng-Man } \\
\text { Rhee's } \\
(1948 \sim 1960)\end{array}$} & $1945 \sim$ & & & $\begin{array}{l}\text { College-administered } \\
\text { test }\end{array}$ & \\
\hline & 1954 & -Illicit admission & $\begin{array}{l}\text { National college } \\
\text { admission unified test } \\
\text { (Qualification test) }\end{array}$ & $\begin{array}{l}\text { College-administered } \\
\text { test }\end{array}$ & \\
\hline & $1955 \sim$ & $\begin{array}{l}\text {-Illicit admission } \\
\text {-Increased } \\
\text { pressure on } \\
\text { applicants } \\
\text {-Leakage of test } \\
\text { questions } \\
\text { Inequality }\end{array}$ & & $\begin{array}{l}\text { College-administered } \\
\text { test (optional) }\end{array}$ & $\begin{array}{l}\text { High school } \\
\text { grade } \\
\text { percentile rank }\end{array}$ \\
\hline \multirow[t]{3}{*}{$\begin{array}{l}\text { Chung-Hee } \\
\text { Park's } \\
(1962 \sim 1979)\end{array}$} & 1962 & $\begin{array}{l}\text {-Academic } \\
\text { ability gaps } \\
\text { between } \\
\text { colleges } \\
\text {-Abnormal high } \\
\text { school education } \\
\text {-Abusing } \\
\text { non-examination } \\
\text { screening option }\end{array}$ & $\begin{array}{l}\text { National college } \\
\text { admissions qualification } \\
\text { test (using the score for } \\
\text { screening) }\end{array}$ & & \\
\hline & 1963 & $\begin{array}{l}\text {-Academic } \\
\text { ability gaps } \\
\text { between } \\
\text { colleges } \\
\text { - Loss of college } \\
\text { autonomy in } \\
\text { selecting } \\
\text { applicants }\end{array}$ & $\begin{array}{l}\text { National college } \\
\text { admissions qualification } \\
\text { test (Qualification test) }\end{array}$ & $\begin{array}{l}\text { College-administered } \\
\text { test }\end{array}$ & \\
\hline & $1964 \sim$ & -Widened & & College-administered & High school \\
\hline
\end{tabular}




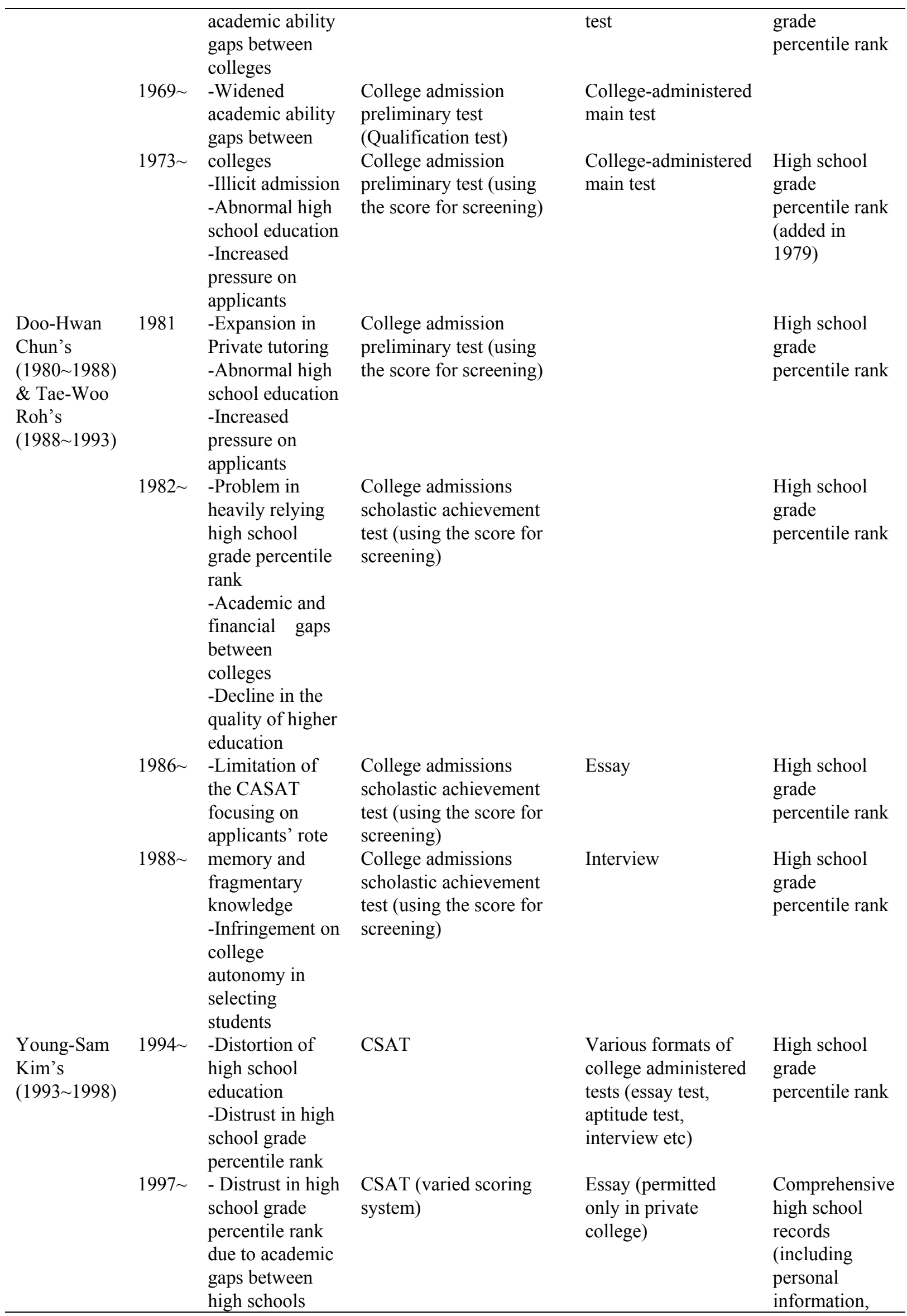




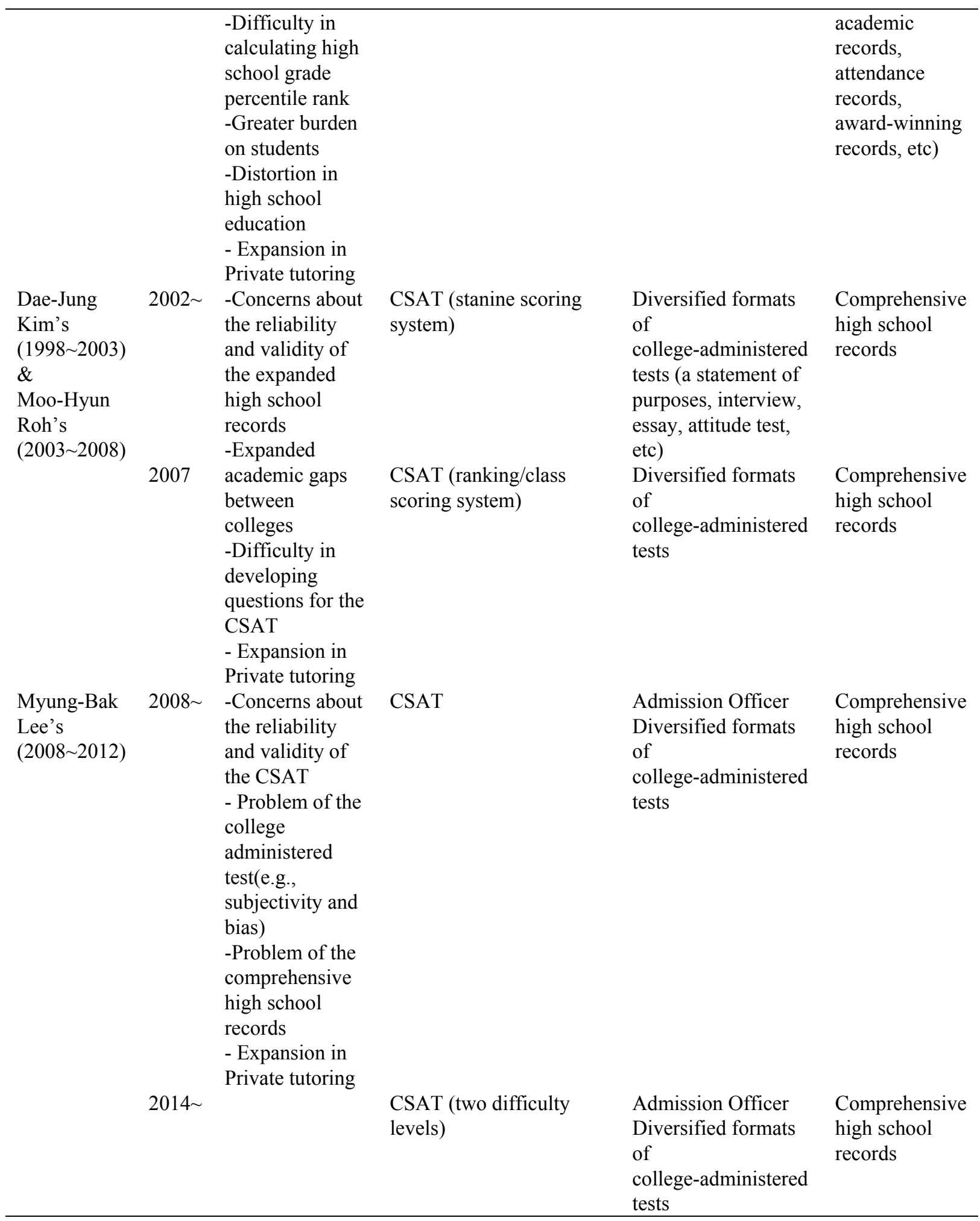

\section{Copyrights}

Copyright for this article is retained by the author(s), with first publication rights granted to the journal.

This is an open-access article distributed under the terms and conditions of the Creative Commons Attribution license (http://creativecommons.org/licenses/by/3.0/). 